\title{
The Removal of Single and Binary Basic Dyes from Synthetic Wastewater Using Bentonite Clay Adsorbent
}

\author{
Olaseni Segun Esan*, Akeremale Olaniran Kolawole, Aboluwoye Christopher Olumuyiwa
}

Department of Chemical Sciences, Adekunle Ajasin University, Akungba-Akoko, Nigeria

\section{Email address:}

lincolnolaseni@yahoo.com (O. S. Esan)

${ }^{*}$ Corresponding author

\section{To cite this article:}

Olaseni Segun Esan, Akeremale Olaniran Kolawole, Aboluwoye Christopher Olumuyiwa. The Removal of Single and Binary Basic Dyes from Synthetic Wastewater Using Bentonite Clay Adsorbent. American Journal of Polymer Science and Technology.

Vol. 5, No. 1, 2019, pp. 16-28. doi: 10.11648/j.ajpst.20190501.13

Received: September 25, 2018; Accepted: March 4, 2019; Published: March 21, 2019

\begin{abstract}
In order to broaden the application of Bentonite clay, an easily obtainable and bio-available low cost adsorbent, it was employed for the decolourization of synthetic wastewater consisting of single and binary basic dyes (Malachite green and Rhodamine b). The adsorbent was used as obtained without any further modification and also characterized for its specific surface area, point of zero charge and its surface functional groups pre and post dyes sorption was determined using Fourier Transform Infrared Spectroscopy (FTIR). Batch adsorption methods were employed in order to study the effects of $\mathrm{pH}$, Ionic strength and contact time in the single solute system. The parameters of sorption of Rhodamine B (RDB) and Malachite green (MG) were obtained and fitted to three isotherm models; Freundlich, Langmuir and Temkin. The Freundlich plot analysis indicated the process occurred via heterogeneous coverage of adsorbent by both dyes. The kinetics of adsorption data were analyzed using the; pseudo-first order, pseudo-second order, Intraparticle diffusion, film diffusion, and Boyd kinetic models. Over the study of these parameters, the film diffusion mechanism was found to predominate in the sorption process of the dyes. Competitive sorption studies were carried out by using both dyes as either the adsorbate of interest or as the interfering specie. The competitive co-coefficient values obtained from interfering MG in RDB removal were significantly lower than those obtained from interfering RDB in MG removal, indicating that the presence of RDB in the aqua matrix had antagonistic effect on MG adsorption by Bentonite.
\end{abstract}

Keywords: Freundlich, Langmuir, Temkin, Adsorption, Malachite Green, Bentonite

\section{Introduction}

Years of increased industrial activities have resulted in the generation of large amount of wastewater containing a number of coloured toxic pollutants, which are polluting the available fresh water continuously. Having realized this basic fact that these coloured pollutants in aqueous systems adversely affect human and animal life, the control of pollution is now a high priority task. The availability of clean water for various activities is becoming the most challenging task for researchers and practitioners worldwide. Dye pollutants are a major source of environmental contamination and colour is the first contaminant that is recognized in wastewater [1]. These water-soluble dyes are recalcitrant, carcinogenic and offer considerable resistance to biodegradation due to their complex structures and high thermal/photo-stability, hence there removal is paramount. Industries such as the textile industries, dye manufacturing industries, paper and pulp mills, tanneries, electroplating factories, distilleries, food companies, and a host of other industries generate and discharge this coloured wastewater [2]. The first synthetic dye was encountered in 1856 by William Perkin Henry in the accidental synthesis of Mauveine but presently over 100,000 dyes have been made and more than $7 \times 10^{5}$ tonnes are produced annually [3]. More than 10,000 dyes are commercially available and about $5-10 \%$ of these are somehow discharged as wastewaters by these industries directly or indirectly into our water bodies [4].

The two conventional methods for the treatment of coloured wastewater are; the biological method and the 
physical/chemical method. Amongst the numerous techniques of dye removal, adsorption which is a physical/chemical method is the procedure of the choice and gives the best results as it can be used to remove different types of colouring materials [5-7]. The major advantage of an adsorption treatment over other methods is due to its costeffectiveness and sludge free clean operation [8].

Over the past decade, Bentonite clay has been successfully employed for the adsorption of dye molecules and metal ions [9]. To date several conventional and non-conventional sorbents have been employed in the removal of these dyes from wastewaters while limited attention has been given to the fact that this wastewater usually contains more than one dye constituent, hence in the removal of one dye constituent the other may either possess an antagonistic or a noninteractive effect on the constituent of interest. This study particularly takes a case study of two different basic dyes (RDB and $\mathrm{MG}$ ) in a binary system and examines the nature of the effect of one on the other. The effects of $\mathrm{pH}$, Ionic strength and contact time were further evaluated and reported for each dyes in their single solute system.

\section{Experimental}

\subsection{Materials}

Bentonite applied in this investigation was obtained from Integrated Mineral Technology Holdings Ltd. (IMT) Australia. It was use without further purification. Malachite green and Rhodamine B were purchase from Sinopharm Chemical Reagent.

\subsection{Methods}

\subsubsection{Characterization of Adsorbent}

The $\mathrm{pH}$ zero point of charge $\left(\mathrm{pH}_{\mathrm{PZC}}\right)$ of the adsorbent was determined via the solid addition method as described by Balistrieri and Murray [10]. This is used to determine the $\mathrm{pH}$ at which the surface of the sorbent exhibits total surface electrical neutrality. The Sear's method [11] was employed in determining the surface area of the adsorbent as well, as surface area is one of the major factors the affects adsorption processes. The surface functional groups present on the adsorbent and their possible involvement in the sorption process was examined from the Fourier Transform Infrared spectrum (FTIR) of the Bentonite which was obtained from the Fourier Transform Infrared Spectrophotometer (Buck Scientific Infrared Spectrophotometer) between $400-4000$ $\mathrm{cm}^{-1}$.

\subsubsection{Adsorbate Quantification}

Malachite green and Rhodamine B concentration in aqueous solution was quantified by the determination of the optical density at the characteristic wavelength using a double beam UV/visible spectrophotometer. A standard solution of the dye was taken and the optical density was determined at different wavelength to obtain a plot of optical density versus wavelength. The wavelength corresponding to the maximum optical density $(\lambda \max =625 \mathrm{~nm}$ and $543 \mathrm{~nm})$, as determined from this plot, was noted and the wavelength was used for the preparation of the calibration curve used in the present studies.

\subsection{Single Solute System Adsorption Experiment}

\subsubsection{Determination of Equilibrium Isotherm and Kinetic Parameters}

Batch adsorption experiment studies were carried out as described by Nidheesh et al [12]. 0.1g of the adsorbent with $50 \mathrm{ml}$ of the dyes (RDB and MG) solutions for each of the desired initial dyes concentration of $2.5-30 \mathrm{mg} / \mathrm{L}$ in a $100 \mathrm{ml}$ capped conical flask and the mixture was agitated on a temperature controlled magnetic stirrer at a constant speed of $1000 \mathrm{rpm}$ until equilibrium is attained. Samples were withdrawn after the equilibrium time ( $3 \mathrm{hrs}$ ) and centrifuged at $4000 \mathrm{rpm}$ for $20 \mathrm{~min}$ for complete separation of the Bentonite particles from the solution and the residual dye concentrations were calculated from the calibration curve. The kinetics of sorption of the dyes was studied by monitoring the uptake of the dyes from aqueous solution at different time intervals $(1,3,5,10,20,30,60,90,120,180)$ in minute [13]. The amount of dye removed per unit mass of the adsorbent was calculated as;

$$
q_{e}=\frac{\left(c_{0}-c_{e}\right)}{m} v
$$

where $\mathrm{C}_{\mathrm{o}}(\mathrm{mg} / \mathrm{L})$ is the initial concentration of the dye, $\mathrm{C}_{\mathrm{e}}$ $(\mathrm{mg} / \mathrm{L})$ equilibrium concentration, $\mathrm{m}$ is the mass of the adsorbent, and $\mathrm{V}$ is the volume of the solution. Percent dye removed $(\% \mathrm{DR})$ was calculated using the equation;

$$
\% D R=\left(\frac{c_{0}-c_{e}}{c_{0}}\right) \mathrm{X} 100
$$

\subsubsection{Influence of $\mathrm{pH}$}

The effect of $\mathrm{pH}$ was examined between $\mathrm{pH} 4$ and $\mathrm{pH} 12$. The different $\mathrm{pH}$ (4 to 12) of the aqueous solution was adjusted by the addition of either $0.1 \mathrm{M} \mathrm{HCl}$ or $0.1 \mathrm{M} \mathrm{NaOH}$ solution via drop wise method when necessary to the dye solutions before the introduction of the adsorbent. The adsorbent-adsorbate ratio was fixed at $0.1 \mathrm{~g}$ to $50 \mathrm{ml}$ while the initial concentration was fixed at $30 \mathrm{mg} / \mathrm{L}$.

\subsubsection{Influence of Ionic Strength}

The dyes solution ionic strength effect was also examined by using $\mathrm{NaCl}$ solution of varying concentrations; $0 \%, 0.1 \%$, $0.5 \%$ and $1 \%$ which is equivalent to ionic strengths of 0.0 $\mathrm{Mol} / \mathrm{L}, 0.017 \mathrm{Mol} / \mathrm{L}, 0.085 \mathrm{Mol} / \mathrm{L}$ and $0.17 \mathrm{Mol} / \mathrm{L}$. The adsorbent-adsorbate ratio was also fixed at $0.1 \mathrm{~g}$ to $50 \mathrm{ml}$ while the initial concentration was fixed at $30 \mathrm{mg} / \mathrm{L}$.

\subsection{Bi-solute System Adsorption Experiment}

The competitive sorption studies was studied in a synthetic wastewater containing only the two solutes (RDB and MG) at different initial concentrations which was between 
$2.5 \mathrm{mg} / \mathrm{L}$ and $30 \mathrm{mg} / \mathrm{L}$ for each of the adsorbate of interest. The concentrations of the adsorbates of interest were varied between $2.5-30 \mathrm{mg} / \mathrm{L}$ while the interfering dyes molecule was kept constant at $30 \mathrm{mg} / \mathrm{L}$ [14]. The competitive sorption equilibrium parameters were obtained by contacting $50 \mathrm{ml}$ solutions of known concentrations of the adsorbate of interest and interfering dye solution in a binary system. The mixture was agitated for $3 \mathrm{hrs}$ and samples withdrawn at the end of the sorption process, centrifuged and the supernatant concentrations of both the adsorbate of interfering solution were determined using the UV - Vis Spectrophotometer at there're respective wavelengths.

\subsection{Error Analysis}

In order to examine the best fit of the different kinetic models to the observed experimental data, an error function is required in the optimization procedure. In the present study, the kinetic models were examined using the linear coefficient of determination, $\mathrm{r}^{2}$, and the non-linear chisquared statistical method, $\chi^{2}$. The coefficient of determination $r^{2}$, represents the percentage of variability in the dependent variables that has been explained by regression line [15].

The value of the coefficient of determination may vary from zero to one and was calculated with the aid of the equation;

$$
r^{2}=\frac{s_{x y}^{2}}{s_{x x}-s_{y y}}
$$

Where $S_{x x}$ is the sum of squares of $\mathrm{x}, S_{y y}$ is the sum of squares of $\mathrm{y}$ and $S_{x y}$ is the sum of squares of $\mathrm{x}$ and $\mathrm{y}$.

In order to evaluate the best of the kinetic models that fit the experimental data, the sorption process was also examined using nonlinear chi-squared $\left(\chi^{2}\right)$ statistical test. The chi-squared statistical test is basically the sum of the squares of the difference between the experimental data and the theoretical data obtained by calculating from models, with each squared difference divided by the corresponding theoretical data obtained by calculating from models. The equivalence of the mathematical statement is;

$$
\chi^{2}=\frac{\sum\left(q_{\text {e.exp }}-q_{\text {e.theo }}\right)}{q_{\text {e.theo }}}
$$

if the data from model and experimental data are similar, then $\chi^{2}$ value will be small and if they are different $\chi^{2}$ will be a large value.

\section{Results and Discussion}

\subsection{Characterization of Adsorbent}

The $\mathrm{pH}$ zero point of charge $\left(\mathrm{pH}_{\mathrm{ZPC}}\right)$ is used to determine the $\mathrm{pH}$ at which the surface of the adsorbent exhibits total surface electrical neutrality. The functional groups present on the adsorbent surface may reside in the positive or negative charge state, depending on the $\mathrm{pH}$ of the system. A large relationship co-exists between the amount of adsorbate adsorbed to the surface of the sorbent and the $\mathrm{pH}_{\mathrm{ZPC}}$ of the adsorbent, which is that; adsorption of positively charged adsorbates will be favoured at $\mathrm{pH}$ values higher than the $\mathrm{pH}_{\mathrm{ZPC}}$ when the surface of the adsorbent is predominantly negatively charged while adsorption of negatively charged sorbent will be favoured at $\mathrm{pH}$ values lower than the $\mathrm{pH}_{\mathrm{ZPC}}$ when the surface of the adsorbent is predominantly positively charged [16]. In the determination of the surface charge of Bentonite used in this study, this showed that it possesses a $\mathrm{pH}_{\mathrm{ZPC}}$ of 2.14 which was supported by literature to be between 2.0 and 3.0 [17-18]. This signifies that the sorbent is suitable for the removal of basic dyes over a large $\mathrm{pH}$ range above 2.14. Its specific surface area was also determined to be $21.5\left(\mathrm{~m}^{2} / \mathrm{g}\right)$. A BET surface area of $20\left(\mathrm{~m}^{2} / \mathrm{g}\right)$ and $31.5\left(\mathrm{~m}^{2} / \mathrm{g}\right)$ was reported by Shu-li et (2009) and Xifang et al (2007) respectively. The difference in the surface area values reported could be ascribed to the method of determination, purity, method of preparation of sample and type of Bentonite. The FTIR spectra of the sorbent pre and post dyes uptake is illustrated in Figure 1. The FTIR spectra of Bentonite before adsorption of dyes showed absorption peak at $3456.80 \mathrm{~cm}^{-1}$ which is linked to the stretching vibration of $\mathrm{H}_{2} \mathrm{O}$, the peak at $1649.60 \mathrm{~cm}^{-1}$ is linked or corresponds to the bending of $\mathrm{H}_{2} \mathrm{O}$, the peak at $1047.20 \mathrm{~cm}^{-1}$ corresponds to the stretching of Si-O, the peak at $920.80 \mathrm{~cm}^{-1}$ denotes the bending vibration of Al-OH-Al. furthermore, FTIR peak at $620.00 \mathrm{~cm}^{-1}$ is associated with $\mathrm{Al}-\mathrm{O}+\mathrm{Si}-\mathrm{O}$ out of plane vibrations while the peak at $537.00 \mathrm{~cm}^{-1}$ denotes Al-O-Si vibration bending. For the FTIR peaks of Malachite green and Rhodamine $\mathrm{B}$, the peak at $1576 \mathrm{~cm}^{-1}$ and $1594 \mathrm{~cm}^{-1}$ respectively, indicates the presence of $=N^{+}$. The peaks at $1467 \mathrm{~cm}^{-1}$ and $1178 \mathrm{~cm}^{-1}$ for MG, peaks at $1468.8 \mathrm{~cm}^{-1}$ and $1176.8 \mathrm{~cm}^{-1}$ for RDB denotes the vibration of the heterocyclic skeleton of the dye molecules. The peaks at $1178 \mathrm{~cm}^{-1}$ and $1176.8 \mathrm{~cm}^{-1}$ for MG and RDB respectively is assigned to $\mathrm{CH}_{3}$. It should be noted that the intensity of the peak at $1047.20 \mathrm{~cm}^{-1}$ present in the FTIR spectra of Bentonite (denoting Si-O vibrations) in the absence of adsorbed dyes (Figure 1) decreases considerably and consistently after the adsorption of each of the dyes to its surface and also in the binary system. A shift in this peak from $1047.2 \mathrm{~cm}^{-1}$ to $1046.40 \mathrm{~cm}^{-1}$ for the adsorption of $\mathrm{MG}$, to $1052.80 \mathrm{~cm}^{-1}$ for the adsorption of RDB and to $1033.60 \mathrm{~cm}^{-1}$ in the presence of both dyes was observed. This may be due to the electrostatic attraction between Si-O group of the Bentonite and the positively charged nitrogen moiety present on both dyes (MG and RDB) signifying the possible involvement of the Si-O group in the sorption process while the shift in peaks confirms the presence of adsorption. 


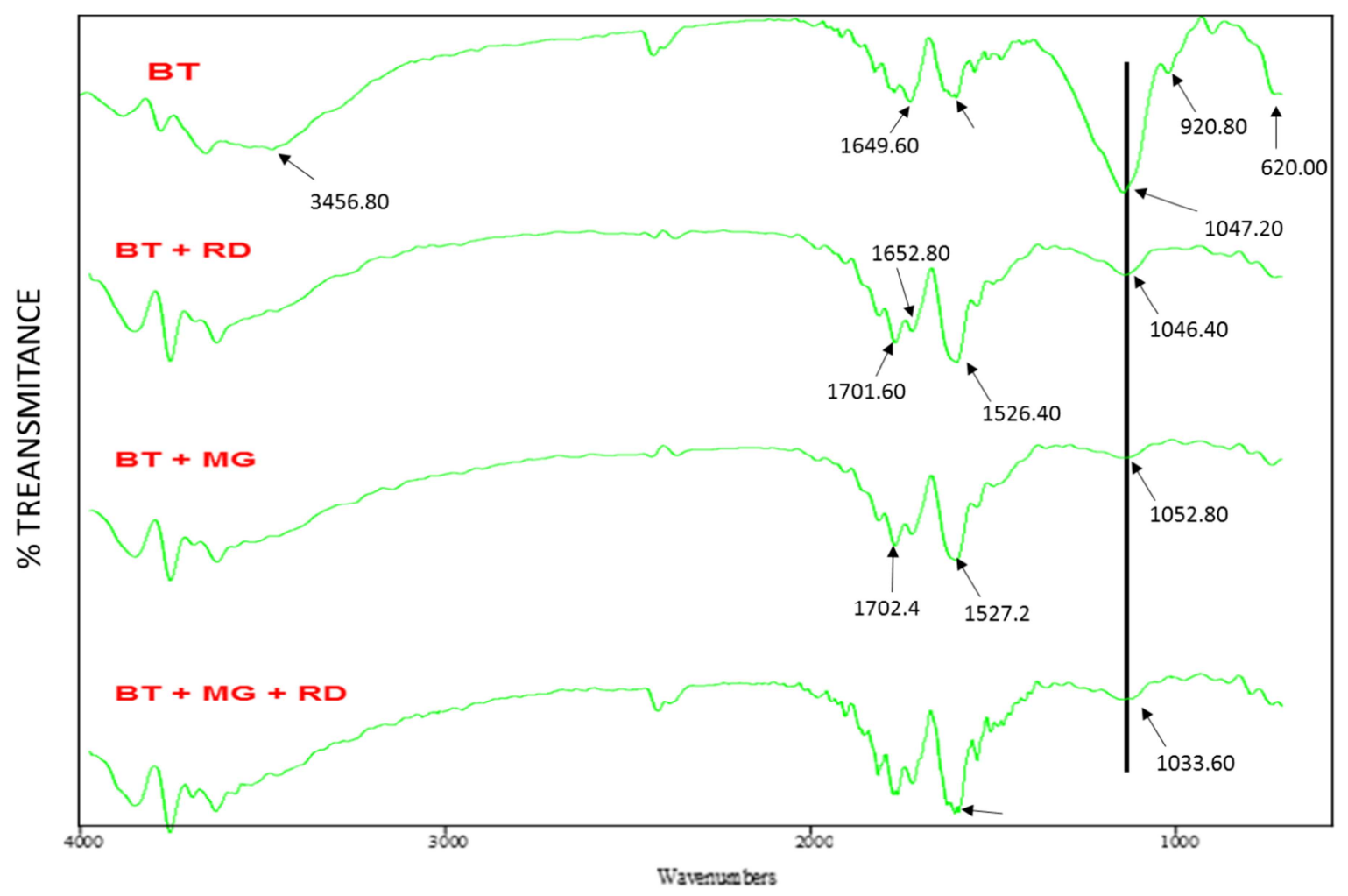

Figure 1. FTIR spectra of Bentonite before and after dye adsorption.

\subsection{Sorption Kinetics of $M G$ and RDB unto Bentonite from Synthetic Wastewater}

To investigate the adsorption process, monitoring of the adsorption kinetics is an important step. It was observed that equilibrium was reached at about $60 \mathrm{mins}$ and the amount of the dyes congregating unto the surface of the adsorbent was highly dependent upon initial concentration. The kinetic parameters of the adsorption of MG and RDB unto Bentonite were evaluated by employing the pseudo-first order and the pseudo-second order kinetic models.

\subsubsection{Pseudo-First Order Kinetic Model}

In cases where adsorption is preceded by diffusion through the boundary layer, the kinetics most have followed the pseudo-first order mechanism as described by Lagergren. [19-20]. The linearized form of the pseudo-first-order equation of Lagergren is generally expressed as:

$$
\ln \left(q_{e}-q_{t}\right)=\ln q_{e}-k_{1} t
$$

where $\mathrm{q}_{\mathrm{e}}$ and $\mathrm{q}_{\mathrm{t}}$ are the sorption capacity at equilibrium and at time $\mathrm{t}$ respectively, $(\mathrm{mg} / \mathrm{g}) . \mathrm{k}_{1}$ is the rate constant of pseudofirst-order adsorption. The plot of $\operatorname{In}\left(q_{e}-q_{t}\right)$ versus $t$ should give a linear relationship from which $\mathrm{k}_{1}$ and $\mathrm{q}_{\mathrm{e}}$ can be deduced from the slope and intercept of the plot, respectively. The pseudo-first-order constants, $\mathrm{k}_{1}$, the correlation coefficients, $r^{2}$, and the chi-square test statistic, $\chi^{2}$, were deduced from the plot of $\ln \left(q_{e}-q_{t}\right)$ versus time ( $\left.\mathrm{t}\right)$, and the respective values obtained are presented in Table 1 and 2 . The correlation coefficients for the pseudo-first order plots for the adsorption of these dyes ranged between 0.812 to 0.976 for RDB (Table 1) while that of MG ranged between 0.871 to 0.994 (Table 2). The calculated $\mathrm{q}_{\mathrm{e}}$ values ( $\mathrm{q}_{\mathrm{e} . \text { theo }}$ ) possess a large disparity from the experimental $\mathrm{q}_{\mathrm{e}}$ values obtained for both dyes. For the applicability of this kinetic model towards the description of the mechanism of the sorption of these dyes unto Bentonite, the nonlinear chisquare test statistic was used to correlate the $\mathrm{q}_{\mathrm{e}}$ values obtained from the theoretical prediction $\left(\mathrm{q}_{\mathrm{e} . \text { theo }}\right)$ and the actual sorption process $\mathrm{q}_{\mathrm{e}}\left(\mathrm{q}_{\mathrm{e}, \mathrm{exp}}\right)$ (Tables 1 and 2 ). The results presented in Tables 1 and 2 showed that the $\chi^{2}$, values were very high, which is an indication that the pseudo-first order model cannot be employed in the description of the adsorption process. Hence, the process does not follow the pseudo-first order adsorption rate expression of Lagergren.

Table 1. Rhodamine B pseudo-first order kinetic parameters.

\begin{tabular}{lllll}
\hline Conc $(\mathbf{m g} / \mathbf{l})$ & $\mathbf{r}^{\mathbf{2}}$ & $\mathbf{K}_{\mathbf{1}}\left(\mathbf{m i n}^{-1}\right)$ & $\boldsymbol{q}_{\boldsymbol{e}(\boldsymbol{e x p})}(\mathbf{m g} / \mathbf{g})$ & $\boldsymbol{q}_{\boldsymbol{e}(\text { theo })}(\mathbf{m g} / \mathbf{g})$ \\
\hline 2.54 & 0.976 & 0.022 & 0.5368 & 0.092 \\
5.01 & 0.812 & 0.021 & 1.3968 & 0.041 \\
9.86 & 0.911 & 0.018 & 2.8951 & 0.122 \\
15.1 & 0.941 & 0.025 & 4.5514 & 0.379 \\
32.25 & 0.947 & 0.414 & 10.2264 & 0.528 \\
\hline
\end{tabular}


Table 2. Malachite Green pseudo-first order kinetic parameters.

\begin{tabular}{llllll}
\hline Conc $(\mathbf{m g} / \mathbf{l})$ & $\mathbf{r}^{\mathbf{2}}$ & $\mathbf{K}_{\mathbf{1}}\left(\mathbf{m i n}^{-1}\right)$ & $\boldsymbol{q}_{\boldsymbol{e}(\text { exp })}(\mathbf{m g} / \mathbf{g})$ & $\boldsymbol{q}_{\boldsymbol{e}(\text { theo })}(\mathbf{m g} / \mathbf{g})$ & $\chi^{2}$ \\
\hline 2.2 & 0.884 & 0.019 & 0.8022 & 0.266 & 1.080866 \\
4.96 & 0.91 & 0.019 & 1.0902 & 0.576 & 0.459031 \\
9.04 & 0.871 & 0.022 & 3.584 & 1.592 & 2.492503 \\
15.11 & 0.994 & 0.023 & 6.4953 & 2.081 & 9.363789 \\
31.43 & 0.884 & 0.021 & 11.4441 & 4.829 & 9.061824 \\
\hline
\end{tabular}

\subsubsection{Pseudo-Second Order Kinetic Model}

The pseudo-second-order kinetic model is represented by the linear equation;

$$
\frac{t}{q_{t}}=\frac{1}{k_{2}} q_{e}^{2}+\frac{1}{q_{e}} t
$$

where $\mathrm{q}_{\mathrm{e}}, \mathrm{q}_{\mathrm{t}}$, and $\mathrm{t}$ have the same meaning as explained above and Where $\mathrm{k}_{2}$ is the pseudo second order rate constant (gmg${ }^{1} \mathrm{~min}^{-1}$ ) which is determined from the intercept and $\mathrm{q}_{\mathrm{e}}$ from the slope of the plot. The plot of $t / q_{t}$ should give a linear relationship if the pseudo-second order kinetic model is applicable.

The initial sorption rate (h) can be obtained from the pseudo-second-order linear plots, as $\mathrm{q}_{\mathrm{t}} / \mathrm{t}$ approaches zero:

$$
h=k q_{e}^{2}
$$

the initial sorption rate, $\mathrm{h}$, the pseudo-second order rate constant, $\mathrm{k}_{2}$, the amount of RDB and MG sorbed at equilibrium, $\mathrm{q}_{\mathrm{e}}$, the linear coefficient value, $\mathrm{r}^{2}$, and the chisquare test statistic function, $\chi^{2}$, obtained are presented in Table 3 and 4 . The values of $h$ and $\mathrm{q}_{\mathrm{e}}$ increased with the increase in the initial concentration of both dyes while the adsorption rate constants decreased with increasing initial concentrations. The large values of the $r^{2}$ and negligible $\chi^{2}$ values is a pointer to the fact that the mechanism of adsorption of the dyes follows the pseudo-second order. Muhammad et al [21-22] have also reported the mechanism of $\mathrm{RDB}$ and $\mathrm{MG}$ respectively to have concurred with the pseudo-second order mechanism.

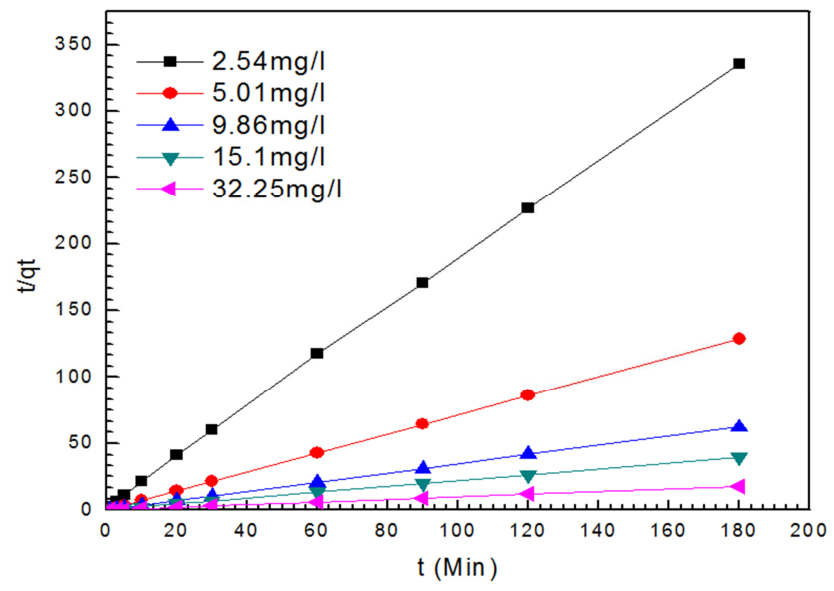

Figure 2. Pseudo second Order Kinetic Plots of adsorption of Rhodamine B unto Bentonite.

\begin{tabular}{|c|c|c|c|c|c|c|c|}
\hline Conc (mg/l) & $\mathbf{r}^{2}$ & $h\left(\min ^{-1}\right)$ & $q_{e}^{2}$ & $\mathrm{k}_{2}\left(\mathrm{gmg}^{-1} \mathrm{~min}^{-1}\right)$ & $q_{e(\exp )}$ & $\left.q_{e(\text { theo })}\right)$ & $\chi^{2}$ \\
\hline 2.54 & 0.999 & 0.351 & 0.29 & 1.212 & 0.5368 & 0.563 & $1.20 \times 10^{-3}$ \\
\hline 5.01 & 1 & 6.306 & 1.956 & 3.224 & 1.3968 & 1.395 & $1.41 \times 10^{-6}$ \\
\hline 9.86 & 1 & 7.692 & 8.402 & 0.916 & 2.8951 & 2.892 & $3.32 \times 10^{-6}$ \\
\hline 32.25 & 1 & 33.333 & 106.28 & 0.314 & 10.2264 & 10.292 & $4.18 \times 10^{-4}$ \\
\hline
\end{tabular}

Table 3. Rhodamine B pseudo-Second order kinetic parameters.

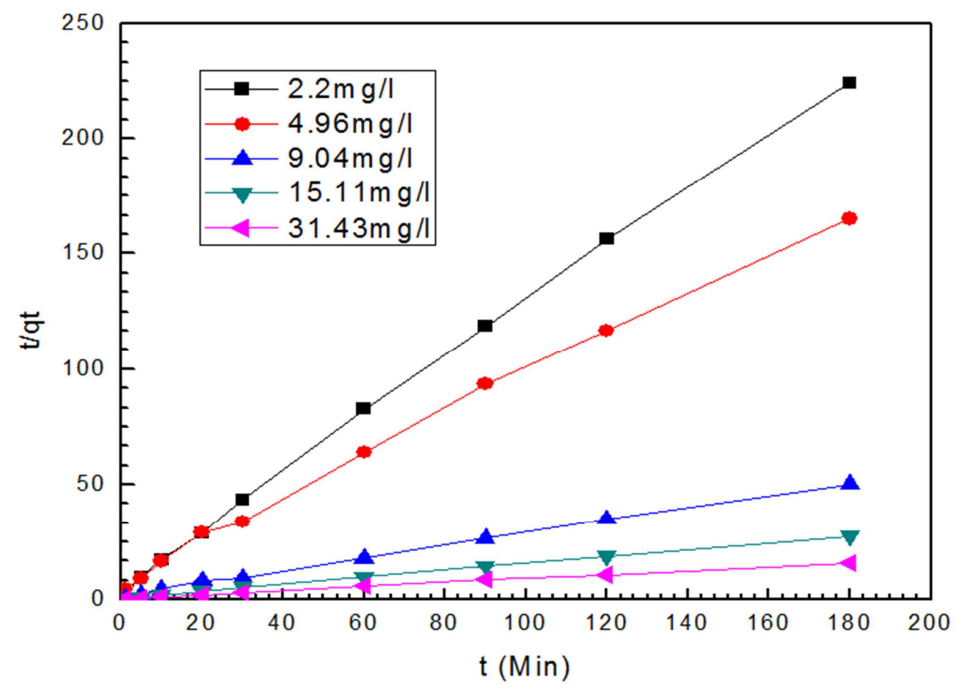

Figure 3. Pseudo second Order Kinetic Plots of adsorption of Malachite Green unto Bentonite. 
Table 4. Malachite Green pseudo-Second order kinetic parameters.

\begin{tabular}{llllllll}
\hline Conc(mg/l) & $\mathbf{R}^{\mathbf{2}}$ & $\mathbf{h}\left(\mathbf{m i n}^{-\mathbf{1}}\right)$ & $\mathbf{q ~ e}^{\mathbf{2}}$ & $\mathbf{k}_{\mathbf{2}}\left(\mathbf{g m g}^{-1} \mathbf{m i n}^{-\mathbf{1}}\right)$ & $\boldsymbol{q}_{\boldsymbol{e}(\boldsymbol{e x p})}$ & $\boldsymbol{q}_{\boldsymbol{e} \text { (theo })}$ & $\chi^{\mathbf{2}}$ \\
\hline 2.2 & 0.998 & 0.205 & 0.649 & 0.316 & 0.8022 & 0.789 & $2.21 \times 10^{-4}$ \\
4.96 & 0.996 & 0.13 & 1.243 & 0.104 & 1.0902 & 1.064 & $6.45 \times 10^{-4}$ \\
9.04 & 0.998 & 0.607 & 13.418 & 0.045 & 3.584 & 3.543 & $4.47 \times 10^{-4}$ \\
15.11 & 0.999 & 1.748 & 43.283 & 0.040 & 6.4953 & 6.444 & $4.08 \times 10^{-4}$ \\
31.43 & 0.998 & 2.179 & 135.208 & 0.016 & 11.4441 & 11.293 & $2.02 \times 10^{-3}$ \\
\hline
\end{tabular}

\subsubsection{Intraparticle Diffusion Model}

Based on the theory proposed by Weber and Moris [23], Intraparticle diffusion model which has been widely applied for adsorption studies was employed to investigate the adsorption mechanism of RDB and MG unto Bentonite. This model is mathematically expressed as;

$$
q_{t}=k_{i d} t^{0.5}+c
$$

Where $\mathrm{C}(\mathrm{mg} / \mathrm{g})$ is the intercept and $\mathrm{K}_{\mathrm{id}}\left(\mathrm{mg} / \mathrm{gmin}{ }^{0.5}\right)$ is the intraparticle diffusion rate constant. The value of $\mathrm{K}_{\mathrm{id}}$ was obtained from the slope of the linear plot of $\mathrm{q}_{\mathrm{t}} \mathrm{vs} \mathrm{t}^{0.5}$ for both dyes (Figure 4 and 5). The value of $\mathrm{C}$ which is given in Table 5 and 6 represent the boundary layer effect [24]. The significance of the deviation from this theory is the difference between the rate of mass transport between the initial and final stages of adsorption (Panday and Singh, 1985) Furthermore, such deviation of straight lines from the origin indicates that the pore diffusion is not the sole ratecontrolling step [25]. The results presented in Figure 4 and 5 show that two separate regions are found in the plot: the first straight portion of the plot is attributed to the macropore diffusion (surface sorption) and the second linear portion is attributed to micropore diffusion (intraparticle diffusion) [26]. In order to actualize the rate controlling step between these two distinct stages by determining the rate of intraparticle diffusion $\left(K_{\mathrm{id}}\right)$ which can be obtained from the slope of the intraparticle diffusion plots. Drawing a comparison between the $K_{\text {id }}$ values of the two stages, it can be observed that the rate-limiting step is the macropore diffusion stage for the adsorption of both dyes (Table 5 and $6)$.

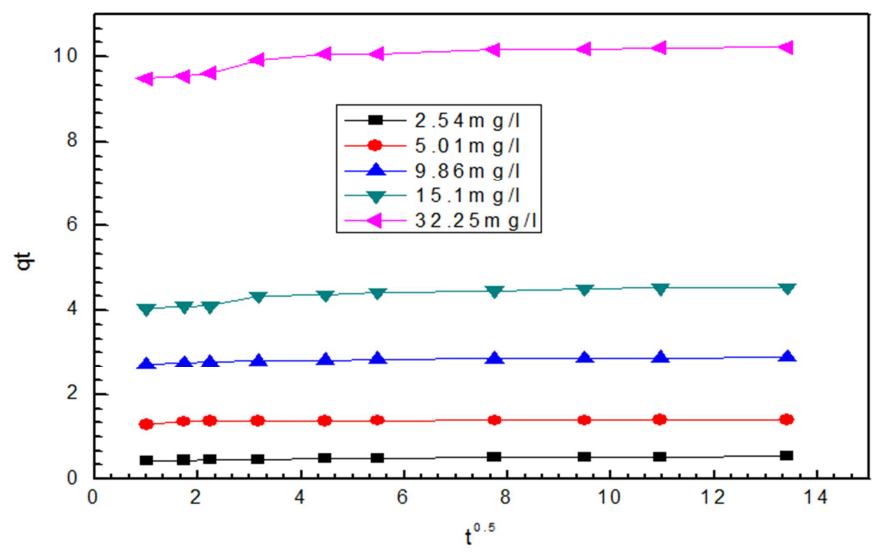

Figure 4. Intraparticle diffusion plot for the sorption of Rhodamine B on Bentonite.

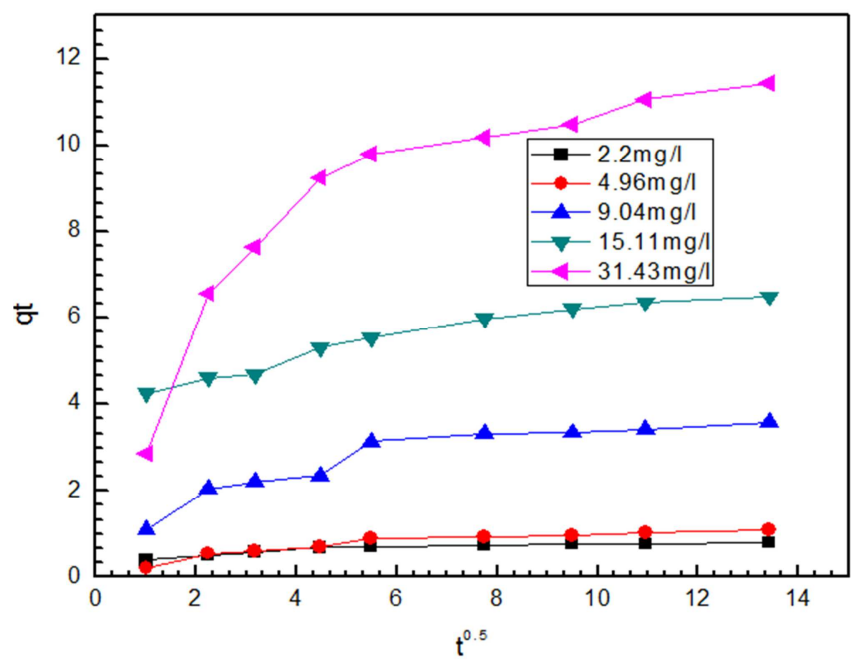

Figure 5. Intraparticle diffusion plot for the sorption of Malachite green on Bentonite. 
Table 5. Intraparticle diffusion parameters for the sorption of Rhodamine B unto Bentonite at different initial concentration (mg/l).

\begin{tabular}{|c|c|c|c|c|c|c|}
\hline \multicolumn{4}{|l|}{ Initial linear portion } & \multicolumn{3}{|l|}{ Second portion } \\
\hline \multirow{2}{*}{ Initial Conc (mg/l) } & \multirow{2}{*}{$K_{\text {id1 }}\left(\mathrm{mg} / \operatorname{gmin}^{0.5}\right)$} & $\mathrm{C}(\mathrm{mg} / \mathrm{g})$ & $\mathbf{r}^{2}$ & \multirow{2}{*}{$\mathrm{K}_{\mathrm{id} 2}\left(\mathrm{mg} / \mathrm{gmin}^{0.5}\right)$} & C & $\mathbf{r}^{2}$ \\
\hline & & (Intercept) & & & \multicolumn{2}{|l|}{ (Intercept) } \\
\hline 2.54 & 0.025 & 0.399 & 0.999 & 0.007 & 0.456 & 0.946 \\
\hline 5.01 & 0.060 & 1.235 & 0.907 & 0.002 & 1.369 & 0.971 \\
\hline 9.86 & 0.045 & 2.673 & 0.991 & 0.009 & 2.781 & 0.926 \\
\hline 15.10 & 0.054 & 3.996 & 0.943 & 0.021 & 4.290 & 0.944 \\
\hline 32.25 & 0.103 & 9.374 & 0.983 & 0.027 & 9.912 & 0.840 \\
\hline
\end{tabular}

Table 6. Intraparticle diffusion parameters for the sorption of malachite green unto Bentonite at different initial concentration (mg/l).

\begin{tabular}{|c|c|c|c|c|c|c|}
\hline \multicolumn{4}{|l|}{ Initial linear portion } & \multicolumn{3}{|c|}{ Second portion } \\
\hline \multirow{2}{*}{ Initial Conc.(mg/l) } & $K_{\text {id1 }}$ & $\mathbf{C}$ & $\mathbf{r}^{2}$ & $\mathbf{K}_{\mathrm{id} 2}$ & $\mathbf{C}$ & $\mathbf{r}^{2}$ \\
\hline & $\left(\mathrm{mg} / \mathrm{gmin}^{0.5}\right)$ & (Intercept) & & $\left(\mathrm{mg} / \mathrm{gmin}^{0.5}\right)$ & (Intercept) & \\
\hline 2.2 & 0.089 & 0.301 & 0.999 & 0.013 & 0.624 & 0.986 \\
\hline 4.96 & 0.181 & 0.065 & 0.894 & 0.038 & 0.607 & 0.834 \\
\hline 9.04 & 0.53 & 0.649 & 0.906 & 0.107 & 2.277 & 0.68 \\
\hline 15.11 & 0.21 & 4.065 & 0.932 & 0.137 & 4.808 & 0.943 \\
\hline 31.43 & 2.25 & 0.897 & 0.949 & 0.235 & 8.353 & 0.973 \\
\hline
\end{tabular}

\subsubsection{Liquid Film Diffusion Model}

Sequel to the inability of the intraparticle diffusion model to adequately describe the sorption mechanism of RDB and MG by Bentonite, the adsorption dynamics was investigated utilizing the liquid film diffusion model. The possible migration of dye molecules from bulk solution to the exterior surface of the sorbent through the liquid film was investigated by utilizing the liquid film diffusion model (equation $\mathrm{x}$ ) in order to determine the rate controlling step [27].

$$
\ln (1-F)=-k_{f d} t
$$

Where $\mathrm{K}_{\mathrm{fd}}\left(\mathrm{min}^{-1}\right)$ is the liquid film diffusion rate constants and $\mathrm{F}=q_{t} / q_{e}$. A linear plot of $\ln (1-F)$ vs $\mathrm{t}$, were tested for both dyes (RDB and MG). From these plots, the overall sorption process yielded linear plots with coefficients of correlation $\left(\mathrm{r}^{2}\right)$ ranging between 0.8121 to 0.9768 with intercepts between -1.7581 to -3.1278 for RDB and 0.8717 to 0.9946 with intercepts ranging between -0.2403 to -1.0645 for MG. The rate constant for the liquid film diffusion $\mathrm{K}_{\mathrm{fd}}$ was between $1.81 \times 10^{-2}-2.27 \times 10^{-1}$ for RDB and between $6.14 \times 10^{-2}-8.87 \times 10^{-2}$ for MG. This is pointer of the fact that as these plots do not pass through the origin (i.e. intercepts less than zero for RDB and MG), the applicability of this model in describing the mechanism of the adsorption of these basic dyes by Bentonite is limited.

Table 7. liquid film diffusion parameters for the sorption of Rhodamine B unto Bentonite at different initial concentration (mg/l).

\begin{tabular}{|c|c|c|c|c|c|c|}
\hline Overall & & & & First Five I & & \\
\hline \multirow{2}{*}{ Initial Conc.(mg/l) } & $\mathbf{k}_{\mathrm{fd} 2}$ & Intercept & $\mathbf{r}^{2}$ & $\mathbf{k}_{\mathrm{fd} 1}$ & Intercept & $\mathbf{r}^{2}$ \\
\hline & \multicolumn{3}{|l|}{ (mg/gmin) } & \multicolumn{3}{|l|}{ (mg/gmin) } \\
\hline 2.54 & 0.227 & -1.758 & 0.977 & 0.08 & -1.484 & 0.994 \\
\hline 5.01 & 0.021 & -3.514 & 0.812 & 0.277 & -2.403 & 0.888 \\
\hline 9.86 & 0.018 & -3.128 & 0.911 & 0.091 & -2.712 & 0.976 \\
\hline 15.1 & 0.025 & -2.476 & 0.941 & 0.034 & -2.176 & 0.891 \\
\hline 32.25 & 0.031 & -2.964 & 0.963 & 0.048 & -2.569 & 0.997 \\
\hline
\end{tabular}

Table 8. liquid film diffusion parameters for the sorption of Malachite green unto Bentonite at different initial concentration (mg/l).

\begin{tabular}{|c|c|c|c|c|c|c|}
\hline Overall & & & & First Five I & & \\
\hline \multirow{2}{*}{ Initial Conc.(mg/l) } & $\mathbf{k}_{\mathrm{fd} 2}$ & Intercept & $\mathbf{r}^{2}$ & $\mathbf{k}_{\mathrm{fd} 1}$ & Intercept & $\mathbf{r}^{2}$ \\
\hline & \multicolumn{3}{|l|}{ (mg/gmin) } & \multicolumn{3}{|l|}{ (mg/gmin) } \\
\hline 2.20 & 0.0191 & -1.1050 & 0.8840 & 0.0688 & -0.6110 & 0.9929 \\
\hline 4.96 & 0.0196 & -0.6044 & 0.9102 & 0.0614 & -0.2403 & 0.8148 \\
\hline 9.04 & 0.0223 & -0.7920 & 0.8717 & 0.0640 & -0.3795 & 0.8362 \\
\hline 15.11 & 0.0232 & -1.1217 & 0.9946 & 0.0237 & -1.0645 & 0.8540 \\
\hline 31.43 & 0.0213 & -0.8480 & 0.8849 & 0.0887 & -0.2752 & 0.9207 \\
\hline
\end{tabular}

\subsubsection{Boyd Kinetic Model}

In order to actualize the rate controlling step involved in the sorption of RDB and MG unto the Bentonite, the kinetic data were further analyzed using the Boyd kinetic model according to the equation [27];

$$
F=1-\left(6 / \pi^{2}\right) \exp \left(-B_{t}\right)
$$

where $B_{t}$ represents the mathematical function of $\mathrm{F}$, and $\mathrm{F}$ is the solute adsorbed fraction at various time $\mathrm{t}$. 


$$
F=\frac{q_{t}}{q_{\infty}}
$$

Where $q_{t}$ is the amount adsorbed at time $t, q_{\infty}$ represents the amount adsorbed at infinite time. (In this study is 180min). A linear form of the Boyd kinetics is written as:

$$
B_{t}=-0.4977-\operatorname{In}\left(1-q_{t} / q_{e}\right)
$$

Hence, the values of $B_{t}$ can be estimated for each value of $F$ using equation 10 . The calculated $B_{t}$ values were plotted against time (Figure 6 and 7), and the linearity test of the $B_{t}$ versus t plot for different initial RDB and MG concentrations was employed to differentiate between the particle diffusion and film diffusion-controlled adsorption process. If the Boyd plot is a straight line passing through the origin (zero intercept), the particle diffusion mechanism predominates. However, if the plots do not pass through the origin (i.e. intercept greater than zero), the film diffusion mechanism predominates. Figure 6 and Figure 7 shows that the Boyd plots for the removal of RDB and MG by Bentonite do not pass through the origin, indicating that the film diffusion mechanism predominates in the adsorption process

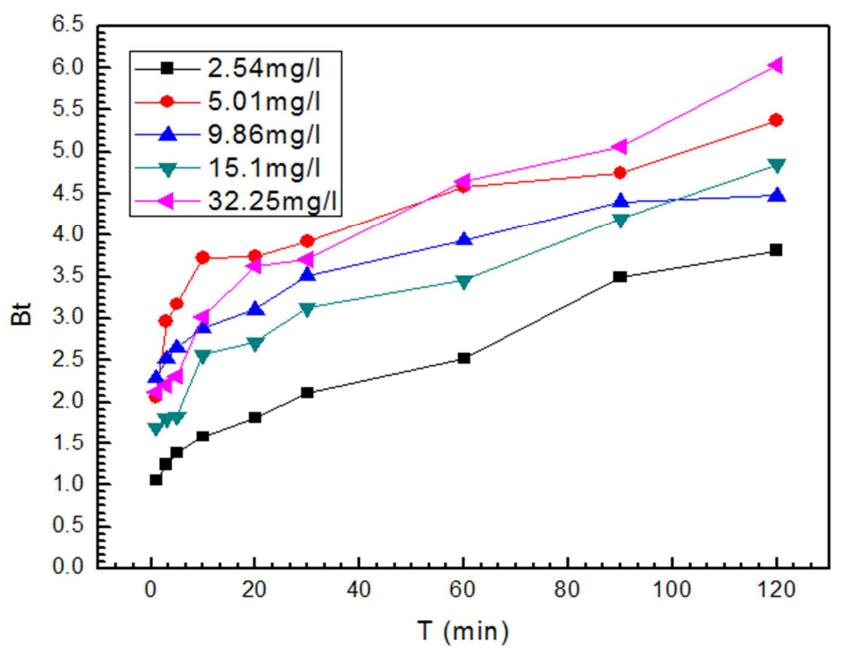

Figure 6. Boyd kinetic plots for the sorption of Rhodamine b unto Bentonite at different initial concentrations.

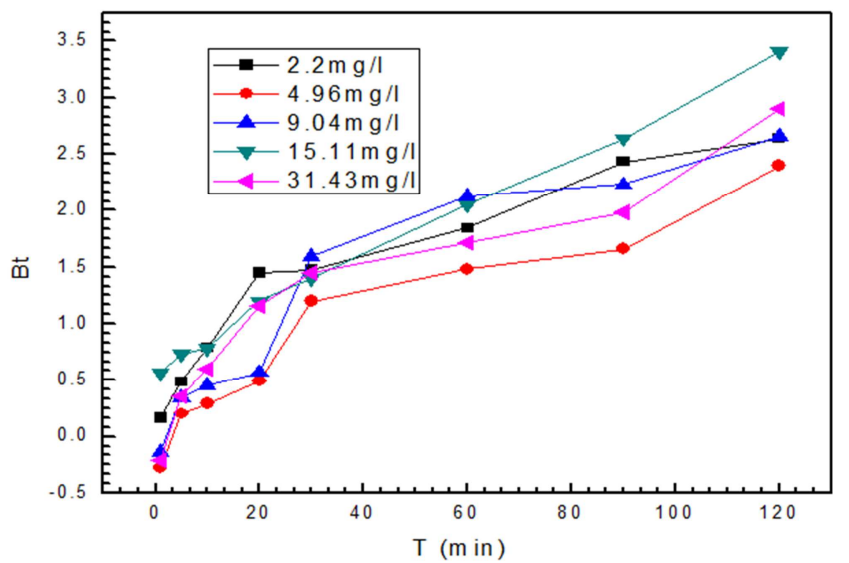

Figure 7. Boyd kinetics plots for the sorption of Rhodamine b unto Bentonite at different initial concentrations.

\subsection{Adsorption Isotherms}

Adsorption equilibrium isotherm is expressed by relating the amount of adsorbate sorbed per gram of sorbent, $\mathrm{q}_{\mathrm{e}}$ $(\mathrm{mg} / \mathrm{g})$, to the equilibrium solution concentration, $\mathrm{C}_{\mathrm{e}}(\mathrm{mg} / \mathrm{L})$, at a fixed environmental condition. In this present study, the Temkin, Langmuir and Freundlich isotherm models were employed in the description of the adsorption process and the isotherm parameters obtained using these models are presented in Table 9.

The linear form of Langmuir's isotherm model is expressed as;

$$
\frac{c_{e}}{q_{e}}=\frac{1}{k_{L} q_{m}}+\frac{c_{e}}{q_{m}}
$$

Where $\mathrm{q}_{\mathrm{m}}$ the maximum value of adsorptive capacity $(\mathrm{mg} / \mathrm{g}), K_{L}$, is the Langmuir constant $(\mathrm{L} / \mathrm{mg})$ which is related to the energy of adsorption are obtained from the intercept and slope of the plot respectively [28]. The constants $q_{m}$ and $K_{L}$ were calculated from the slope and intercept of the linear plot of $\mathrm{C}_{\mathrm{e}} / \mathrm{q}_{\mathrm{e}}$ versus $\mathrm{C}_{\mathrm{e}}$. From Table 9, the low correlation coefficient values $\left(\mathrm{r}^{2}\right)$ obtained for Langmuir isotherm model, 0.465 for $\mathrm{RDB}$ and 0.042 for $\mathrm{MG}$ is an indication that this isotherm model did not express the experimental data for both dyes, suggesting that the surface of Bentonite is heterogeneous and not homogeneous in nature. The essential characteristics of the Langmuir isotherm, used to predict the adsorption efficiency, was expressed in terms of a dimensionless equilibrium parameter $R_{L}$, defined by $R_{L}=\frac{1}{1+K_{L} C_{O}}$, where Co $(\mathrm{mg} / \mathrm{l})$ is the highest concentration of adsorbate. The value of $\mathrm{R}_{\mathrm{L}}$ indicates if Langmuir isotherm is unfavorable $\left(R_{L}>1\right)$, linear $\left(R_{L}=1\right)$, favorable $\left(0<R_{L}>1\right)$ or irreversible $\left(R_{L}=0\right)$. The values of $\mathrm{R}_{\mathrm{L}}$ at $\mathrm{Co}=30 \mathrm{mg} / \mathrm{l}$ in the present study were found to be $1.6058 \times 10^{-3}$ for RDB and 0.718 for malachite green at $298.15 \mathrm{k}$, indicating that the adsorption of these basic dyes unto Bentonite is favorable.

The Freundlich adsorption isotherm is the first mathematical fit to an isotherm published [29]. It is a purely empirical isotherm which describes the adsorption onto a heterogeneous surface with the linear equation;

$$
\ln q_{e}=\ln k_{f}+\frac{1}{n} \ln c_{e}
$$

Where $\mathrm{q}_{\mathrm{e}}$ is the adsorptive capacity which is the quantity of the material adsorbed per unit gram of the adsorbent $(\mathrm{mg} / \mathrm{g}), \mathrm{C}_{\mathrm{e}}$ is the equilibrium adsorbate concentration $(\mathrm{mg} / \mathrm{L})$; $K_{\mathrm{f}}$, the Freundlich isotherm constant related to adsorption capacity (indicating the quantity of dye adsorbed onto the adsorbent) and n, the Freundlich isotherm constant related to adsorption intensity (which indicates the favorability of the adsorption process) can be obtained from the intercept and slope of the plot respectively [29-30]. Therefore, the plot of $\mathrm{Inq}_{\mathrm{e}}$ versus $\mathrm{InC}_{\mathrm{e}}$ gives a straight line of slope $1 / \mathrm{n}$ and intercepts $\log K_{\mathrm{F}}$. It can be observed from Table 9 above that 
the Freundlich isotherm provides a very good fit to the experimental data possessing $\mathrm{r}^{2}$ of 0.980 for RDB and 0.905 for MG suggesting that the sorption of the dyes occurred via heterogeneous coverage of the surface of the adsorbent. The values of $\mathrm{K}_{\mathrm{F}}$ which denotes the sorption capacities of the adsorbent towards the dyes was found to be $0.386 \mathrm{mg} / \mathrm{g}$ for RDB and $0.8055 \mathrm{mg} / \mathrm{g}$ for MG. RDB and $\mathrm{MG}$ adsorption onto Bentonite clay is considered to be unfavorable because the Freundlich exponent values of $\mathrm{n}$ (which determines the intensity and feasibility of the adsorption process) were less than 1 ( 0.73 for RDB and 0.98 for MG). Generally, the value of $1 / \mathrm{n}$ less than 1 and the value of $\mathrm{n}$ in the range of $2-10$ indicates that the adsorption process is favorable, 1-2 moderately difficult and below 1 poor adsorption characteristics [31].

The Temkin isotherm is based on the assumption that the free energy of adsorption is dependent on the surface coverage and takes into account the interactions between adsorbents and dye molecules. The linear form of the Temkin isotherm model equation [32] is expressed as.,

$$
q_{e}=B \ln A_{T}+\left[\frac{R T}{b_{t}}\right] \ln c_{e}
$$

Where: $A_{T}$ is the equilibrium binding constant $[\mathrm{L} / \mathrm{g}], \mathrm{b}_{\mathrm{t}}$ is the adsorption constant $[\mathrm{J} / \mathrm{mol} \mathrm{K}], \mathrm{R}$ is the universal gas constant $(8.314 \mathrm{~J} / \mathrm{mol} \mathrm{K}), \mathrm{T}$ is absolute temperature value [298K], B is a constant related to the heat of sorption [J/mol]. The Temkin isotherm model display a correlation coefficient values of 0.899 for RDB and 0.754 for MG which are lower than those observed from the Freundlich isotherm model as shown in Table 9. Therefore, the Temkin isotherm model do not describe the mechanism of sorption of these dyes unto Bentonite.

Table 9. Results of Isotherm analysis.

\begin{tabular}{llll}
\hline Mathematical methods & parameters & Rhodamine B & Malachite green \\
\hline \multirow{3}{*}{ Langmuir isotherm } & $\mathrm{r}^{2}$ & 0.465 & 0.042 \\
& $\mathrm{~K}_{\mathrm{L}}\left(\mathrm{dm}^{3} / \mathrm{mg}\right)$ & 20.689 & 0.013 \\
& $\mathrm{q}_{\mathrm{m}}(\mathrm{mg} / \mathrm{g})$ & 9.434 & 55.556 \\
\multirow{3}{*}{ Freundlish isotherm } & $\mathrm{r}^{2}$ & 0.980 & 0.905 \\
& $\mathrm{~K}_{\mathrm{F}}(\mathrm{mg} / \mathrm{g})$ & 0.386 & 0.805 \\
& $\mathrm{n}$ & 0.732 & 0.987 \\
\multirow{5}{*}{ Temkin isotherm } & $\mathrm{r}^{2}$ & 0.899 & 0.754 \\
& $\mathrm{~B}(\mathrm{~J} / \mathrm{mol})$ & 4.457 & 3.758 \\
& $\mathrm{~A}_{\mathrm{T}}(\mathrm{L} / \mathrm{g})$ & 0.612 & 0.894 \\
& $\mathrm{~b}_{\mathrm{T}}(\mathrm{J} / \mathrm{molK})$ & 555.880 & 659.279 \\
\hline
\end{tabular}

\subsection{Effect of $\mathrm{pH}$}

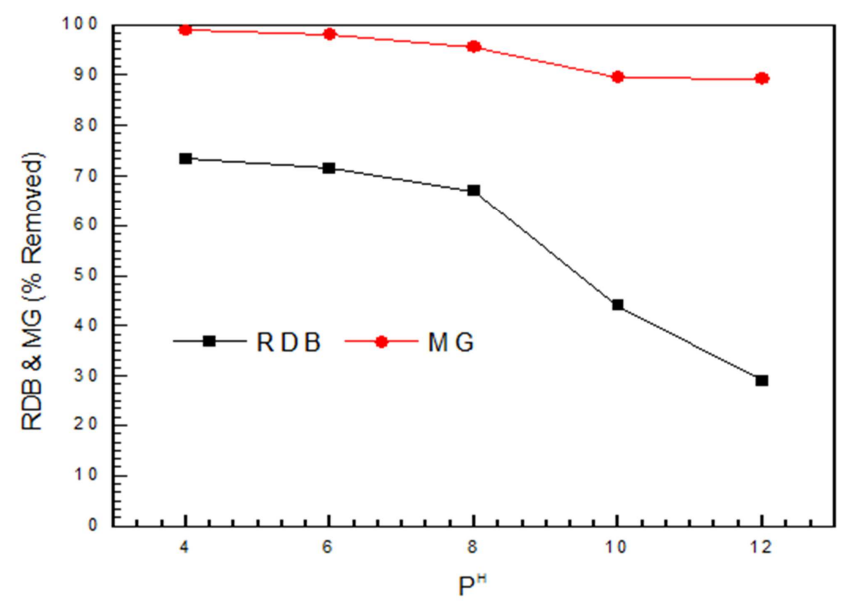

Figure 8. Percentage removal of Rhodamine B and Malachite Green unto Bentonite at different initial $\mathrm{pH}$ values and a constant concentration of 30 $m g / L$ for each

It must be emphasized that $\mathrm{pH}$ is one of the most important variables to be considered in adsorption studies. The $\mathrm{pH}$ of the aqueous medium alters the net charge present on the surface of the adsorbent, the ionization degree of the adsorbate molecules and the dissociation extent of the functional groups present on the adsorbent [33]. The variations in the total percentage of the dyes removed at different $\mathrm{pH}$ and initial concentration of $30 \mathrm{mg} / \mathrm{l}$ for RDB and $\mathrm{MG}$ are shown in Figure 8. For these dyes, the maximum percentage removal was attained at $\mathrm{pH} 4$ (in excess of $70 \%$ for $\mathrm{RDB}$, and excess of $90 \%$ for $\mathrm{MG}$ ). The trend in the plot also shows that the percentage removal peaked at $\mathrm{pH} 4$ and maintained a steady decline until $\mathrm{pH} 12$. This variation in behavior of the adsorption can be explained on the basis of point of zero charge of the adsorbent $\left(\mathrm{pH}_{\mathrm{ZPC}}=2.14\right)$ as well as the structures of the dyes. At $\mathrm{pH}$ below the point of Zero charge of the adsorbent (2.14) the surface of the sorbent has a high positive charge density and under this condition the uptake of positively charged dyes would be low. With increasing $\mathrm{pH}$ i.e. beyond the point of zero charge, negative charge density on the surface of the adsorbent increases, resulting in an enhancement in the removal of these positively charged dyes. Also as a result of the acidic groups on these dyes that dissociates with increasing $\mathrm{pH}$, giving rise to negative charge on the dyes which accounts for the reduction in the percentage removed in these dyes at higher $\mathrm{pH}$.

\subsection{Effect of Ionic Strength}

It is a well-known fact the ionic strength of aqueous solutions affects the electrostatic attraction and repulsion between adsorbents and adsorbates to a very large extent and as such these electrolytes affects the adsorption behavior by competing with the adsorbate's ions on the surface of 
adsorbents. This effect is of high importance in order to verify the existence of the hydrophobic - hydrophobic interactions which is the attraction between the nonpolar groups of the dye and the adsorbent [21]. From the result of the effect of ionic strength on these cationic dyes presented in Figure 9, it can be observed that an increase in ionic strength $(0-0.17 \mathrm{~mol} / \mathrm{L})$ of the solution led to an increase in the total percentage of the dyes that were removed as compared to the solution without the salt $(\mathrm{NaCl})$. This justified the fact that hydrophobic - hydrophobic and coulombic interactions may be the dominant attraction force for the RDB and MGBentonite adsorption system. A similar case of this type of interaction was reported by Mohammad et el., [21]. This is because in solution of high ionic strength, the electrostatic attraction mechanism is suppressed due to the competition between the cationic dyes molecules with the $\mathrm{Na}^{+}$present for the active sites on the adsorbent surface, leading to reduction in electrostatic attraction between the dyes and the adsorbent surface. High ionic strength also enhances hydrophobic hydrophobic interactions by compression of the electrical double layer that moves particles much closer together which leads to increase in dye adsorption as observed in Figure 9. $\mathrm{Hu}$ et al. [34] also reported a similar observation for the sorption of methyl orange, methylene blue and neutral red. It has been reported that ionic strength greatly influences particle aggregation by altering electrostatic interactions between adsorbates and sorbents. An increase in ionic strength of a solution has been described to suppress electrostatic repulsion thereby promoting particle aggregation [35-36].

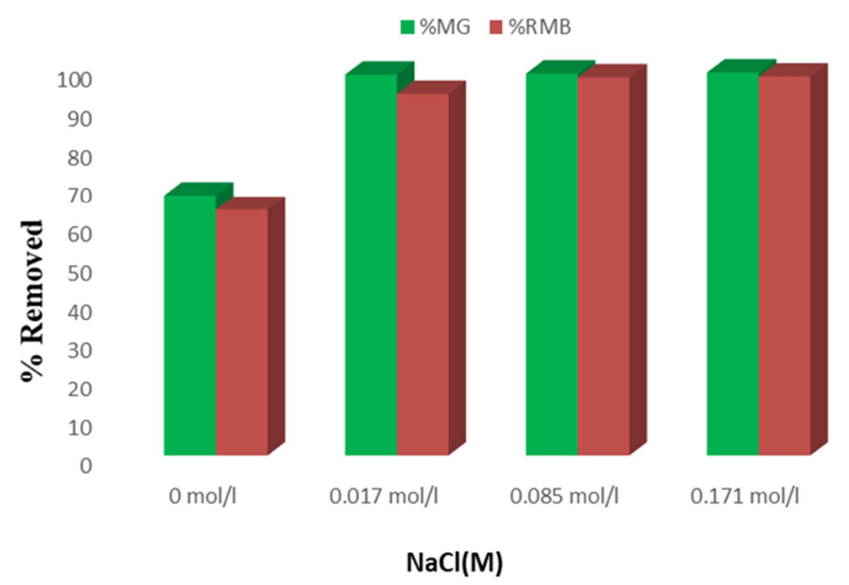

Figure 9. Effect of salt on the adsorption of Rhodamine B and Malachite Green unto Bentonite at the Initial dye concentration of $30 \mathrm{mg} / \mathrm{l}$.

\section{Competitive Sorption in Synthetic Wastewater}

Following the conformation of the isotherm equilibrium data (i.e RDB and MG removal by Bentonite) in single solute system to the Freundlich equilibrium isotherm model, the extended Freundlich multicomponent adsorption isotherm proposed by Sheindorf et al, [14], (i.e. the Sheindorf-RebuhnSheintuch (SRS) equation) was employed in the determination of the extent of competitive effects of MG on $\mathrm{RDB}$ removal by Bentonite on one hand, and the extent of competitive effect of RDB on MG removal by Bentonite on the other hand.

The assumptions in the derivation of the SRS equation incorporated states that each component must individually obey the Freundlich isotherm and an exponential distribution of site adsorption energies must exist.

The general form of the SRS equation can be expressed as;

$$
q_{I}=K_{I} C_{I}\left(\sum a_{I J} C_{J}\right)^{n_{1}-1}
$$

Where, $q_{I}$ is the adsorption of component, I, per gram weight of adsorbate $(\mathrm{mg} / \mathrm{g}) ; \mathrm{C}_{\mathrm{I}}$ and $\mathrm{C}_{\mathrm{J}}$ are the concentrations of $\mathrm{I}$ and $\mathrm{J}$ in the equilibrium solution $(\mathrm{mg} / \mathrm{L}) ; \mathrm{K}_{\mathrm{I}}$ and $\mathrm{n}_{\mathrm{I}}$ are the Freundlich constants obtained for, I, in a singlecomponent system; and $\mathrm{a}_{\mathrm{IJ}}$ is the competition coefficient for the adsorption of component, I, in the presence of component, J. Sheindorf et al. [14] successfully applied this model to the competitive equilibrium adsorption of $p$ nitrophenol and benzene sulphonate onto activated carbon. For the bicomponent system study in this case, the sorption of each component is given by the following equation;

\subsection{RDB/MG System}

$$
q_{R}=K_{R} C_{R}\left(C_{R}+a_{R M} C_{M}\right)^{n_{1}-1}
$$

Where RDB is the adsorbate of interest and $\mathrm{MG}$ is the interfering ionic species.

\section{2. $M G / R D B$ System}

$$
q_{R}=K_{M} C_{M}\left(a_{M R} C_{R}+C_{M}\right)^{n_{1}-1}
$$

Where MG is the adsorbate of interest and ${ }^{2} \mathrm{RDB}$ is the interfering ionic species.

The linear form of the bicomponent isotherm equation can be written for RDB/MG system as;

$$
\frac{C_{R}}{C_{M}}=\frac{\beta_{R}}{C_{M}}-a_{R M}
$$

and as MG/RDB system as

$$
\frac{C_{M}}{C_{R}}=\frac{\beta_{M}}{C_{R}}-a_{M R}
$$

Where $\beta_{R}=\left(\frac{K_{R} C_{R}}{q e_{R}}\right)^{\frac{1}{1-n_{1}}}$ and $\beta_{M}=\left(\frac{K_{M} C_{M}}{q e_{M}}\right)^{\frac{1}{1-n_{2}}}$

As expressed above, the competition coefficients were determined from the intercept of a straight-line plot of $C_{R}$ against $\beta_{\mathrm{R}}$ in Eqn 17 . 


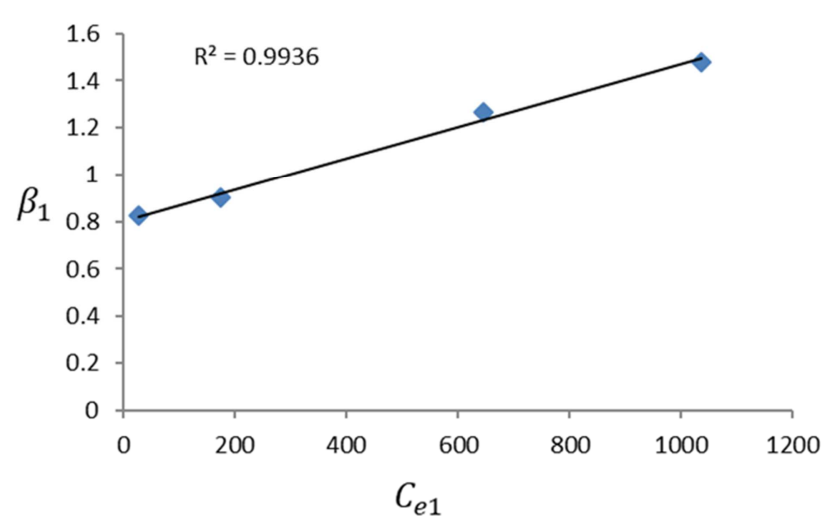

Figure 10. Experimental results presented in the linear form of the multicomponent adsorption isotherm: Rhodamine $B$ in the presence of Malachite Green at constant concentration system.

Figure 10 shows the extended Freundlich plot for Rhodamine B-Malachite Green system. The correlation coefficient was found to be 0.993 which shows a very good linearity of the plot and indicates the applicability of the extended Freundlich equation to describe the competitive adsorption behavior of the binary mixture. The values of the competition coefficients were determined from the intercept of the above plot (Figure 10). However, it should be noted that since by definition $a_{R M}=1 / a_{M R}$ (i.e. $a_{12}=$ $1 / a_{21}$ as described by Sheindorf et al, (1981), only one of the coefficients is required [14]. The competitive coefficients of $\mathrm{RDB}$ in the presence $\mathrm{MG}\left(a_{R M}\right)$ and the competitive coefficients of Malachite Green in the presence of RDB $\left(a_{M R}\right)$ from $2.5 \mathrm{~m} / 1$ to $30 \mathrm{mg} / 1$ is presented in Table 10 below.

Table 10. Summary of competitive coefficients values for the binary-solute system of Rhodamine b and malachite green in synthetic wastewater system.

\begin{tabular}{lll}
\hline Conc (mg/L) & $\mathbf{a}_{\mathbf{R M}}$ & $\mathbf{a}_{\mathbf{M R}}$ \\
\hline 2.9 & 0.2509 & 3.9851 \\
5.49 & 0.3077 & 3.2498 \\
11.71 & 0.3178 & 3.1467 \\
15.96 & 0.3059 & 3.2686 \\
39.57 & 0.2946 & 3.3943 \\
\hline
\end{tabular}

Deb et al. [37] proposed that the value for the competitive coefficient range from zero (complete lack of competition) to greater than zero (normally less than 10) for a high degree of competition. An overview of the values of the competitive coefficients obtained showed that the values of the $a_{R M}$ (Table 10) were far lower than that of the $a_{M R}$ in the synthetic wastewater system. The values of the $a_{R M}$ ranged between 0.251 and 0.318 while that of the $a_{M R}$ ranged between 3.15 and 3.99. These showed that the competitive effects of $\mathrm{MG}$ in RDB sorption by Bentonite were insignificant, since the values of the competition coefficient were below unity [38]. The values of the competitive coefficient of RDB in MG sorption by Bentonite were very high (Table 10). The values observed for the competitive coefficients of both MG and RDB, as interfering ionic specie, in their respective systems, signifies that the presence of $\mathrm{RDB}$ in the aqua matrix had antagonistic effects on the sorption of MG by the sorbent while the presence of MG had non-interactive effects on the sorption of RDB by Bentonite [39].

\section{Conclusions}

This study evaluated the use of a readily bio-available and inexpensive Bentonite as a low-cost adsorbent for the removal of basic dyes in single and binary system. The FTIR characterization revealed the presence of silanol and aluminol groups on the surface of the Bentonite which was responsible for the sorption of these basic dyes. The sorbent was found to possess a high adsorption potential for MG than $\mathrm{RDB}$ which is possibly due t the presence of the acidic group $-\mathrm{COOH}$ - on the RDB which MG do not possess. The $\mathrm{COOH}$ - groups stimulates an electrostatic repulsion between $\mathrm{RDB}$ and Bentonite. The sorption of both dyes was found to be highly dependent on various environmental conditions such as; $\mathrm{pH}$, Ionic strength, contact time and initial dye concentrations. The equilibrium data analysis revealed heterogeneous nature of the Bentonite which was confirmed by the fitting of the experimental data to the Freundlich isotherm model. The extremely high values of $\mathrm{R}^{2}$ and the predicted values of the equilibrium sorption capacity $\mathrm{q}_{\mathrm{e}}$ which was very much in agreement with experimental data for all initial RDB and MG concentrations confirms that the sorption process follows a pseudo-second-order mechanism. The competitive effects of the presence of $M G$ in the sorption of RDB by Bentonite were insignificant (less than unity), thus, it could be concluded that Malachite Green has noninteractive effect in the sorption of Rhodamine $\mathrm{B}$ by Bentonite. Whereas the competitive effect of the presence of $\mathrm{RDB}$ in the sorption of MG were very high (greater than unity), thus it could be concluded that RDB is antagonistic in the sorption of MG by Bentonite.

\section{References}

[1] Banat IM, Nigam P, Mc Mullan G, Marchant R, Singh D (1996). Microbial decolourization of textile dye containing effluents. Bioresource Technology 58, 217-227.

[2] McKay, G; Porter, J. F; Prasad, G. R. (1999). The removal of dye colours from aqueous solutions by adsorption on low-cost materials, Water, Air, Soil Pollution. 114, 423-438.

[3] McMullan, G.; Meehan, C.; Conneely, A.; Nirby, N.; Robinson, P.; Nigam, I.; Bannat, M. and Marchant, S. W. F. (2001). Mini-review: Microbial decolorization and degradation of textile dyes. Appl. Microbiol. Biotechnol., 56, $81-87$.

[4] Goldberg, S. (2005). Equations and Models describing Adsorption Processes in Soils. Chemical Processes in Soils, Soil Science Society of America (SSSA). SSSA, Wisconsin. p 489.

[5] Derbyshire, F., Jagtoyen, M., Andrew, R., Rao, A., MartinGullon, I., Grulke, E., (2001) Carbon Materials in Environmental Applications, In: Radovic, L. R. (Ed.), Chemistry and Physics of Carbon, 27, Marcel Dekker, New York, $1-66$. 
[6] Ho YS, Mckay G (2003). Sorption of dyes and copper ions onto biosorbents, Proc. Biochem. 38: 1047-1061.

[7] Jain, A. K., Gupta, V. K., Bhatnagar, A. S. (2003) Utilization of industrial waste products as adsorbents for the removal of dyes. J. Hazard. Mater., B, 101, 31-42.

[8] Gupta, V. K.; Suhas. (2009). Application of low-cost adsorbents for dye removal-A review. J. Environ. Manag. 2009, 90, 2313-2342.

[9] Tahir, H.; Hammed, U.; Sultan, M.; Jahanzeb, Q. (2010). Batch adsorption technique for the removal of malachite green and fast green dyes by using montmorillonite clay as adsorbent. Afr. J. Biotechnol, 9, 8206-8214.

[10] Balistrieri, L. S. and Muray, J. W. (1981). The surface chemistry of Geothile $(\alpha \mathrm{FeooH})$ in major ion sea water. American Journal of Science, 281, 788-806.

[11] Sears G. W (1956) Determination of Specific Surface Area of Colloidal Silica by Titration with Sodium Hydroxide Anal. Chem. 28, 1981-1983.

[12] Nidheesh, P. V., Gandhimathi, R., Ramesh, S. T. and Singh, T. S. A. (2012). Adsorption and Desorption Characteristics of Crystal Violet in Bottom Ash Column. Journal of Urban and Environmental Engineering, 6(1): 18-29.

[13] Olaseni S. E., Oladoja N. A., Owoyomi O., Aboluwoye C. O., and Osundiya M. O (2014). Adsorption of Brilliant Green onto Luffa Cylindrical Sponge: Equilibrium, Kinetics, and Thermodynamic Studies. ISRN Physical Chemistry.

[14] Sheindorf, Ch. Rebhun, M. and Sheintuch, M., (1981) . A Freundlich-type multicomponent isotherm, J. Colloid and Interface Sci., 79, 136-142.

[15] Oladoja N. A., Akinlabi A. K., (2009). Congo Red Biosorption on palm kernel seed coat. Industrial and Engineering Chemistry Research, 48, 6188-6196.

[16] Nomanbhay MS, Palanisamy K. (2005) Removal of heavy metal from industrial waste using chitosan coated oil palm shell charcoal. Elect. J. Biotechnol, 8, 43-53.

[17] Hashen F. S. (2012) Adsorption of Methylene Blue from aqueous solutions using $\mathrm{Fe}_{3} \mathrm{O}_{4} /$ Bentonite nanocomposite. Hydrol Current Res 3: 143- 148.

[18] Akpomie K. G, Dawodu F. A (2015) Potential of a low-cost bentonite for heavy metal abstraction from binary component system. Beni-suef university journal of basic and applied sciences $4,1-13$.

[19] Lanregren, S. (1889) "About the theory of so-called adsorption of soluble substances," Kungliga Svenska Vetenskapsakademiens Handlingar, 24, 1-39,

[20] Ho, Y. S. (2004). Citation Review of Lagergren kinetic rate equation on adsorption reactions. Scientometrics 59, 171-177.

[21] Muhammad K. D., Linda B. L. (2016). The removal of Rhodamine $\mathrm{B}$ dye from aqueous solution using Casuarina Equisefolia Needles (CEN) as adsorbent. Journal Cogent Environmental Science 2, 1-14.

[22] Muhammad K. D., Linda B. L. Lim. (2015). Application of Casuarina Equisefolia Needles (CEN) for the removal of methylene blue and malachite green dyes from aqueous solution. Alexandria Engineering Journal 54, 2015, 12531263.
[23] Weber Jr., W. J., Morris, J. C. and Sanit, J. (1963) Kinetics of Adsorption on Carbon from Solution. Journal of the Sanitary Engineering Division, American Society of Civil Engineers, 89, 31-38.

[24] Kannan N. and Sundaram M. M (2001). Kinetics and mechanism of removal of methylene blue by adsorption on various carbons - a comparative study, Dyes and Pigments, $51,25-40$.

[25] Poots, V. J. P.; McKay, G.; Healy, J. J. (1978) Removal of basic dye from effluent using wood as an adsorbent. J. Water Pollut. Control Fed. 50, 926-939.

[26] Lakshmi, U. R., Srivastava, V. C, Mall, I. D, Lataye, D. H. (2009) Rice husk ash as an effective adsorbent: evaluation of adsorptive characteristics for indigo carmine dye, Journal of Environmental Management, 90, 710-720.

[27] Boyd G. E., Adamson A. W., Myers Jr L. S (1947). The exchange adsorption of ions from aqueous solutions by organic zeolites. II. Kinetics J Am Chem Soc, 69, 2836-2848.

[28] Alshabanat, M. Alsenani, G. and Almufarij, R. (2013). Removal of Crystal Violet Dye from Aqueous Solutions onto Date Palm Fiber by Adsorption Technique. Journal of Chemistry, Volume 2013, Article ID 210239, 1-6.

[29] Freundlich, H. (1906). Ueber die Adsorption in Loesungen. Zeitschrift Fur Physikalische Chemie-Stochiometrie Und Verwandtschaftslehre, 57, 385-470.

[30] Runping, H., Pan, H., Zhaohui, C., Zhenhui, Z., and Mingsheng, T. (2008). Kinetics and isotherms of Neutral Red adsorption on peanut husk. Journal of Environmental Sciences, 20: 1035-1041.

[31] Rahman M. A., Ruhul A. S. M. \& Shafiqul A. A. M. (2012). Removal of Methylene Blue from Waste Water using Activated Carbon prepared fromRice Husk. Dhaka University Journal of Science, 60, 185-189.

[32] [32]Temkin, M. and Pyzhev, V. (1940) Kinetics of Ammonia Synthesis on Promoted Iron Catalysts. Acta Physicochimica URSS, 12, 217-222.

[33] Nandi B. K., Goswami A. Purkait M. K (2009) Adsorption characteristics of brilliant green dye on kaolin, Journal of Hazardous Materials, 161, 387-395.

[34] Hu, Y., Gou, T., Ye, X., Li, Q., Gou, M., Liu, H., and Wu, Z. (2013). Dye adsorption by resins: effect of ionic strength on hydrophobic and electrostatic interaction. Chemical Engineering Journal, 228, 392-397

[35] Mercer K. L, Tobiason J. E. (2008). Removal of arsenic from high ionic strength solutions: effects of ionic strength, $\mathrm{pH}$, and preformed versus in situ formed HFO, Environ. Sci. Technol. $42,3797-3802$.

[36] Piret F. Su B.-L. (2008) Effects of $\mathrm{pH}$ and ionic strength on the self-assembly of silica colloids to opaline photonic structures, Chem. Phys. Lett. 457, 376-380.

[37] Deb D. L, Datta N. P (1967). Effect of associating anions on phosphorus retention in soil, Plant Soil. 26, 303-316.

[38] Wu C.-H, Kuo, C.-Y. Lin, C.-F, Lo, S.-F. (2002) Modeling competitive adsorption of molybdate, sulfate, selenate, and selenite using a Freundlich-type multi- component isotherm, Chemosphere 47, 283-292. 
[39] Oladoja, N. A., Hu, S., Drewes, J. E., Helbreich, B. (2016). Insight into defluoridation efficiency of nano magnesium oxide in groundwater system contaminated with hexavalent chromium and fluoride. Separation and Purification Technology 162, 195-202. 